Supplement Information for:

\title{
A low activity ion source for measurement of atmospheric gases by CIMS
}

Young Ro Lee ${ }^{1}$, Yi Ji ${ }^{1}$, David J. Tanner ${ }^{1}$, L. Gregory Huey ${ }^{1}$

$5{ }^{1}$ School of Earth and Atmospheric Sciences, Georgia Institute of Technology, Atlanta, 30332, USA

Correspondence to: L. Gregory Huey (greg.huey@eas.gatech.edu)

This document contains four figures, totaling 4 pages. 
a)

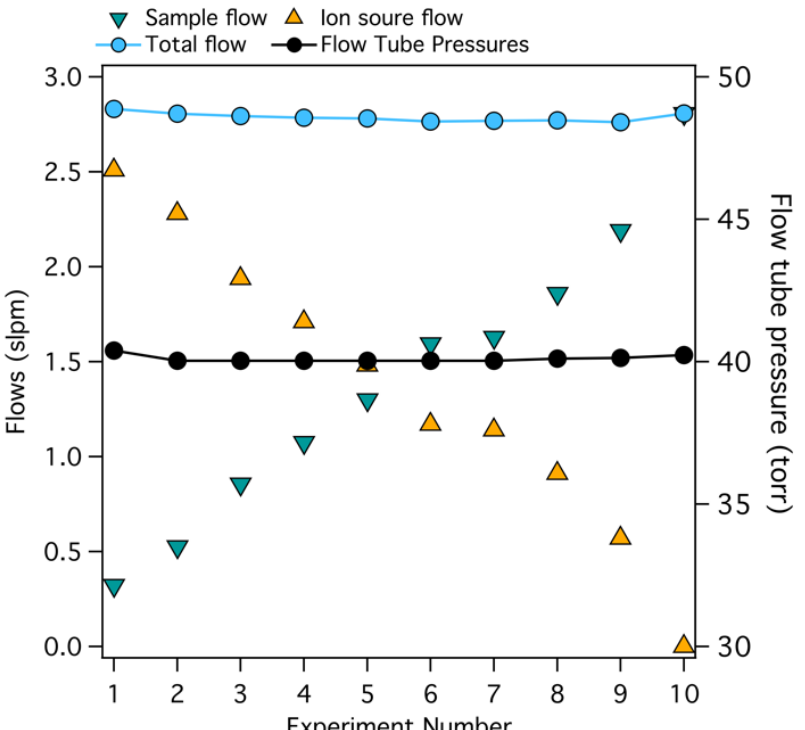

b)

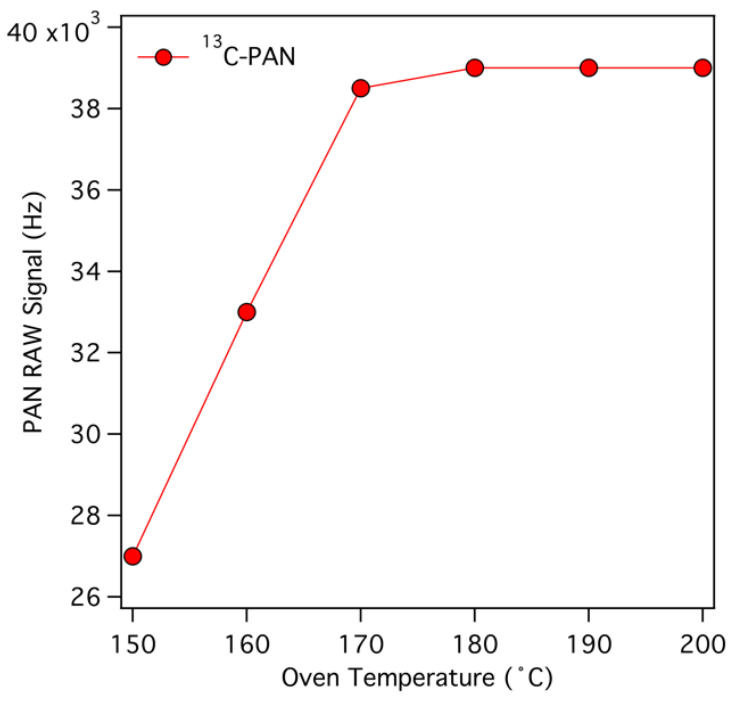

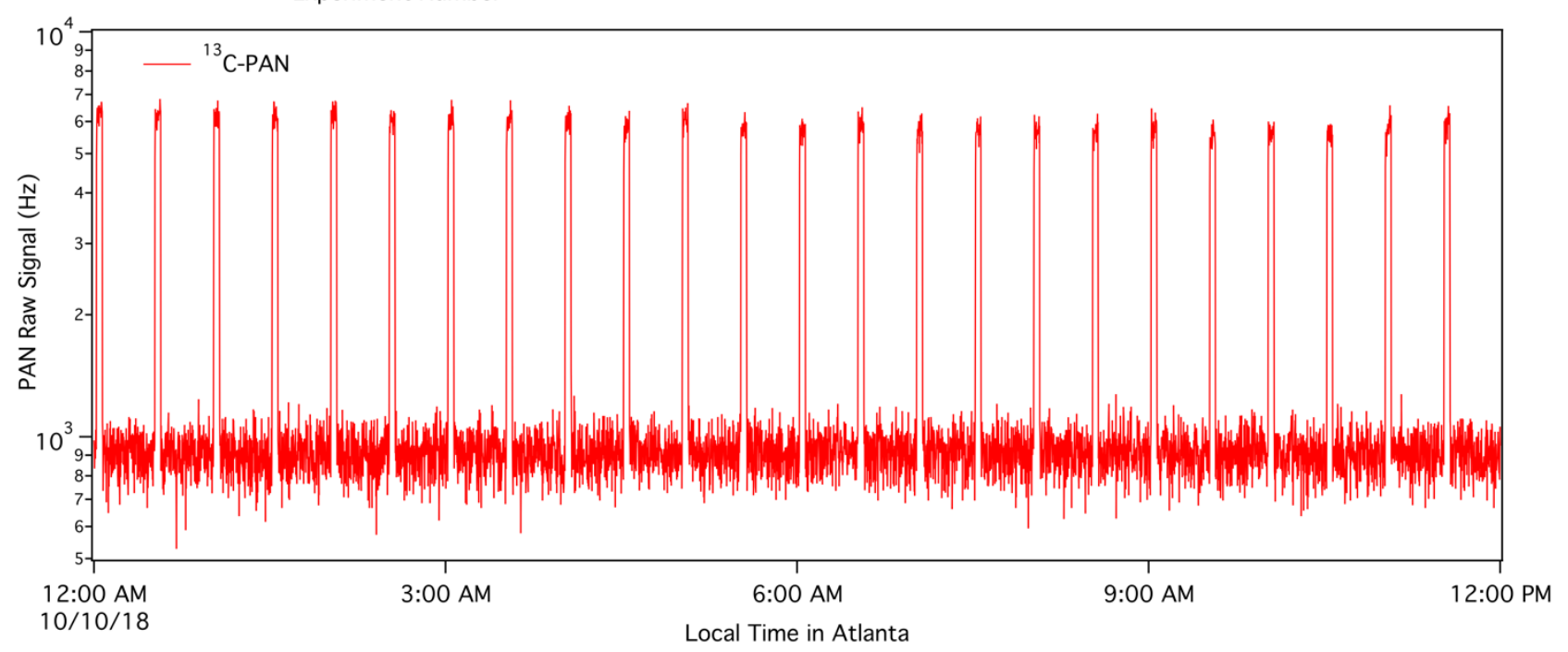

Figure S1. (a) An example of flows controlled by AVO at 40 torr flow tube pressure. (b) PAN calibration signal as a function of temperature. The rate coefficient for the thermal decomposition of PAN (at 453

$25 \mathrm{~K}$ and 100 torr) is $\approx 790 \mathrm{~s}^{-1}$ (Atkinson et al., 2006; IUPAC, 2018), so that PAN calibration standard should be fully thermally dissociated within the residence time of $\sim 40 \mathrm{~ms}$. This is confirmed by measurement of the calibration signal whilst varying the inlet temperature. (c) Time series of PAN calibration signal while sampling ambient air in Atlanta, showing no obvious interference by ambient species such as $\mathrm{NO}$ and $\mathrm{NO}_{2}$. 


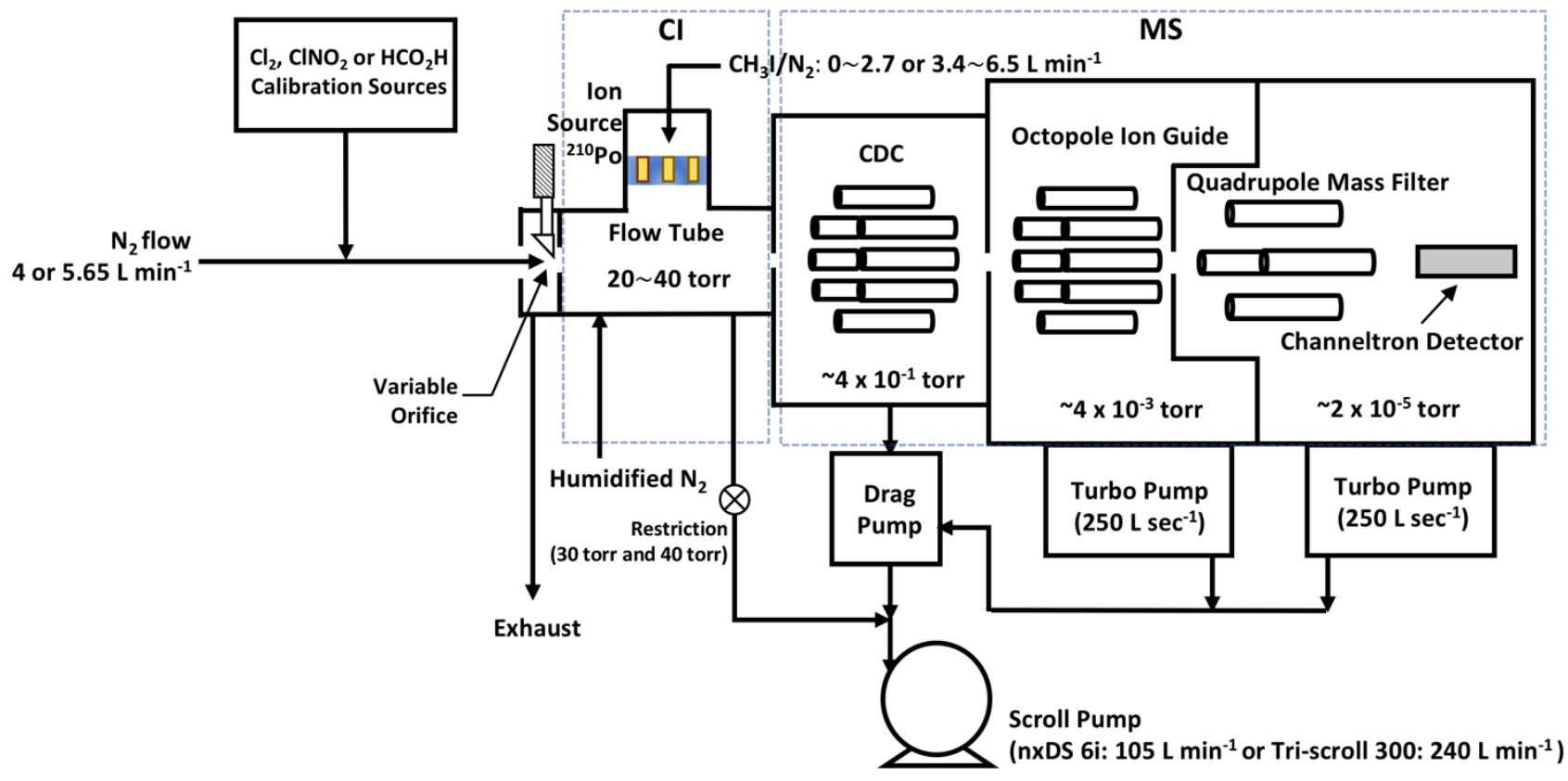

Figure S2. Schematic diagram of the lodide-Adduct CIMS. The nitrogen flows with calibration gas enter 35 the flow tube through the AVO (automatic variable orifice).

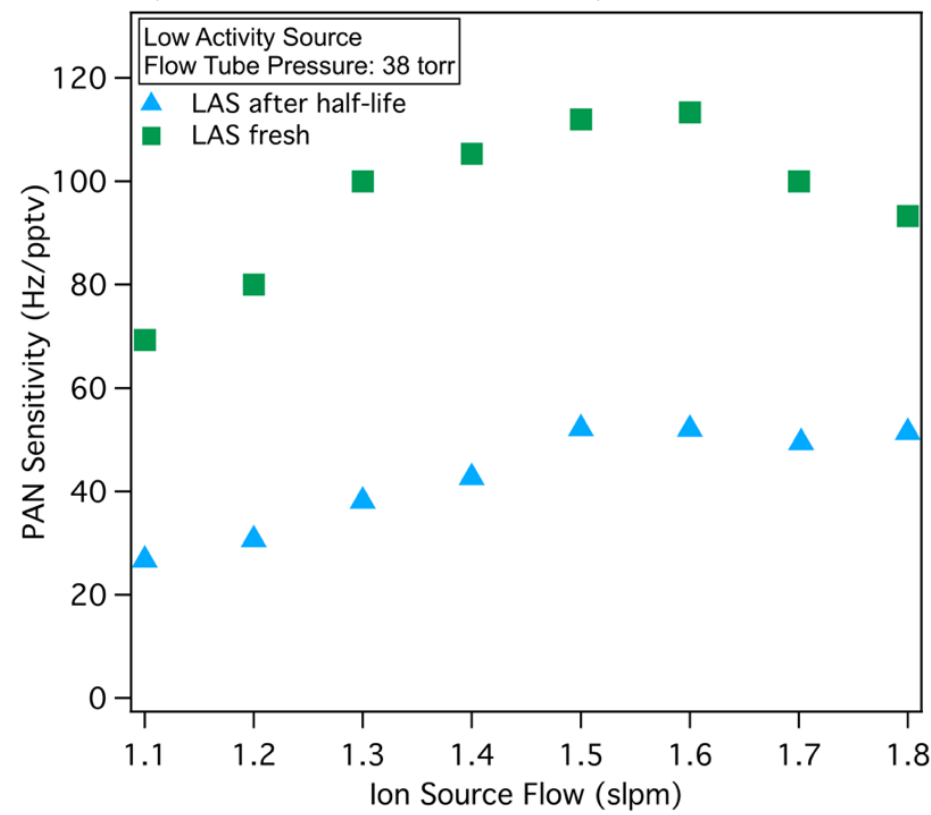

Figure S3. Time dependence of the sensitivity of the LAS. The sensitivity of a fresh (green square) and one half-life aged (cyan triangle) LAS for PAN. 


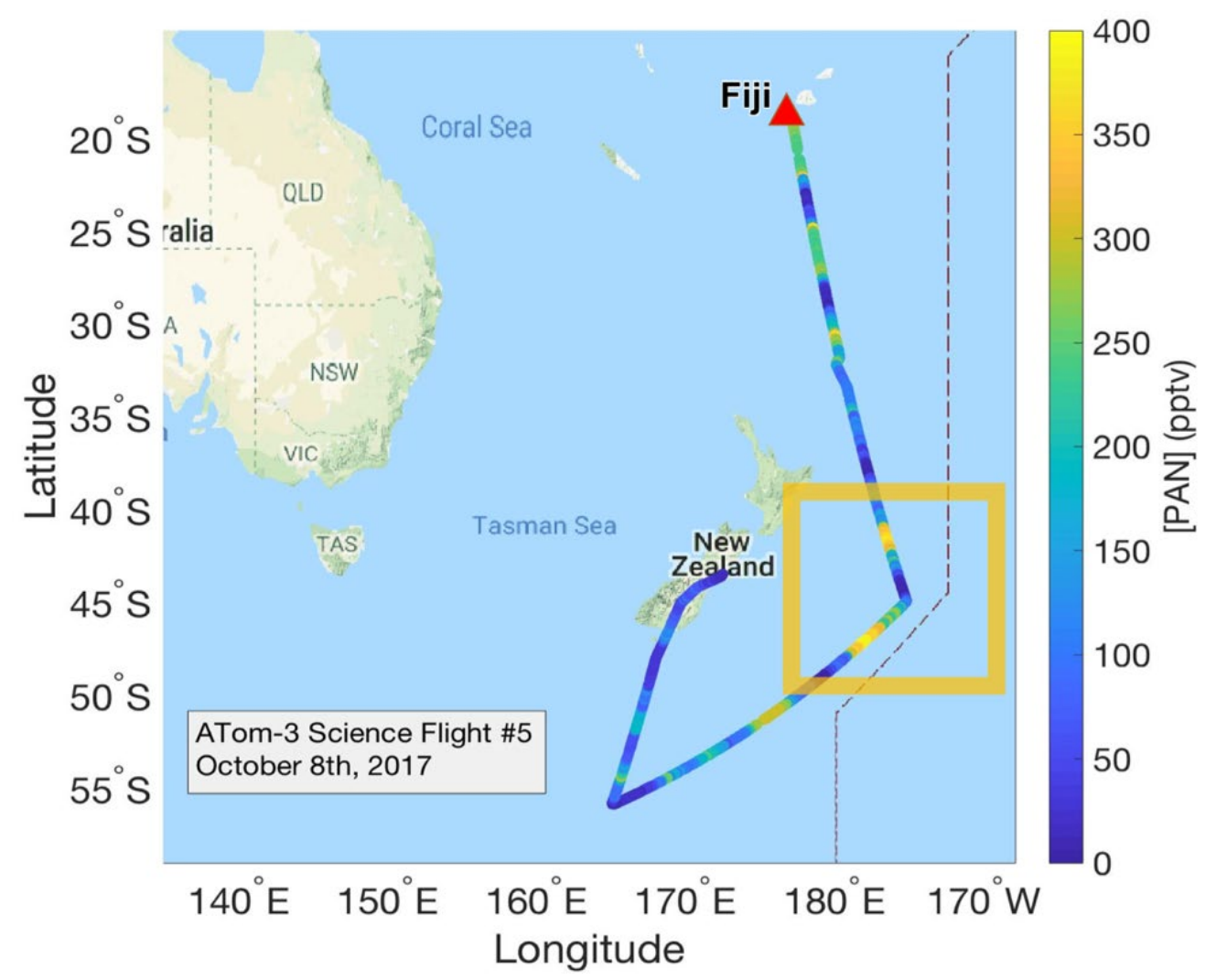

Figure S4. Flight map of the ATom-3 science flight \#5 from Fiji to New Zealand. Orange box highlights the location of the southern hemisphere plume presented in Figure $5 b$. 